九州大学学術情報リポジトリ

Kyushu University Institutional Repository

\title{
Application of tritium tracer techniques to observation of hydrogen on surface and in bulk of $\mathrm{F} 82 \mathrm{H}$
}

\section{Otsuka, Teppe i}

Interdisciplinary Graduate School of Engineering Sciences, Kyushu University

Tanabe, Tetsuo

Interdisciplinary Graduate School of Engineering Sciences, Kyushu University

Tokunaga, Ken

Research Institute of Applied Mechanics, Kyushu University

Yoshida, Naoaki

Research Institute of Applied Mechanics, Kyushu University

他

http://hdl. hand le. net/2324/26030

出版情報 : Journal of Nuclear Materials. 417 (1/3)，pp.1135-1138，2011-10-01. Elsevier バージョン:

権利関係: (C) 2010 Elsevier B.V. 
[00336]

\title{
Application of Tritium Tracer Techniques to Observation of Hydrogen on Surface and in Bulk of F82H
}

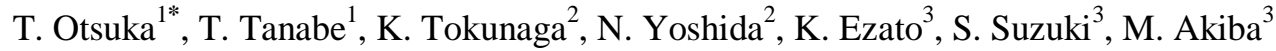 \\ 1 Interdisciplinary Graduate School of Engineering Sciences, Kyushu University, Higashi-ku Hakozaki \\ 6-10-1, Fukuoka 812-8581, Japan, t-otsuka@ nucl.kyushu-u.ac.jp \\ 2 Research Institute of Applied Mechanics, Kyushu University, Kasugakoen 6-1, Kasuga-shi, Fukuoka \\ 816-8580, Japan \\ 3 Japan Atomic Energy Agency, Naka-shi, Ibaraki 311-0193, Japan
}

[Corresponding Author]

Name $\quad$ : Teppei Otsuka

Postal address : Higashi-ku Hakozaki 6-10-1, Fukuoka 812-8581, Japan

Telephone number : +81-92-642-4139

Fax number $\quad:+81-92-642-4139$

E-mail address $\quad$ : t-otsuka@nucl.kyushu-u.ac.jp 


\title{
Application of Tritium Tracer Techniques to Observation of Hydrogen on Surface and in Bulk of F82H
}

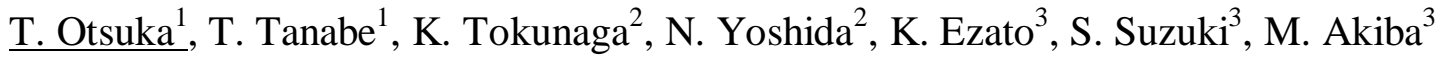

1 Interdisciplinary Graduate School of Engineering Sciences, Kyushu University, Higashi-ku Hakozaki 6-10-1, Fukuoka 812-8581, Japan

2 Research Institute of Applied Mechanics, Kyushu University, Kasugakoen 6-1, Kasuga-shi, Fukuoka 816-8580, Japan

3 Japan Atomic Energy Agency, Naka-shi, Ibaraki 311-0193, Japan

\begin{abstract}
Hydrogen including a trace amount of tritium was loaded on the edge surface of an F82H rod. After the loading, the rod was held at 298 or $323 \mathrm{~K}$ to allow hydrogen diffuse in and release out. Tritium tracer techniques have been applied to determine hydrogen depth profiles and hydrogen release rates by using an tritium imaging plate technique and a liquid scintillation counting technique, respectively. The depth profiles were composed of a surface localized component within $200 \mu \mathrm{m}$ of the surface and a diffused component extending over $1 \mathrm{~mm}$ in depth. The apparent hydrogen diffusion coefficients obtained from the depth profile of the diffused component are near the extrapolated value of the literature data determined at higher temperatures. The surface localized component, which is attributed to trapping at surface oxides and/or defects, was released very slowly to give smaller apparent diffusion coefficients than those determined from the diffused component.
\end{abstract}

Keywords: F82H, Tritium, Hydrogen, Diffusion, Trapping, Surface 


\section{Introduction}

Low activation ferritic steels have attracted much attention for their potential wide application as structural materials in fusion reactors. In particular, the iron alloy $\mathrm{F} 82 \mathrm{H}$, a reduced activation ferritic/martensitic steel developed by Japan Atomic Energy Agency (JAEA), is planned to be used in a DEMO reactor in Japan. A safety concern is for possible tritium permeation through this alloy if it is used as coolant pipes or first walls of the reactor, even at locations remote from the plasma. Although hydrogen permeation and diffusion in $\mathrm{F} 82 \mathrm{H}$ have been studied previously, the temperature range of the studies were limited to temperatures above $573 \mathrm{~K}$ except for two cases [1,2].

In previous work [1], we applied a tritium tracer technique to determine the apparent hydrogen diffusion coefficient in a steel ( $\mathrm{Fe}$ with $8 \% \mathrm{Cr}$ and $2 \% \mathrm{~W}(8 \mathrm{Cr} 2 \mathrm{~W})$ ) similar to $\mathrm{F} 82 \mathrm{H}$ around room temperature (RT). Although the data agreed with the extrapolation of Serra's data [2] obtained at the temperatures above $373 \mathrm{~K}$ to lower temperature range, the temperature dependence showed a significant deviation to lower values for temperatures below $473 \mathrm{~K}$, which is very similar to hydrogen trapping seen in hydrogen diffusion in pure Fe. This motivated us to revisit hydrogen diffusion in F82H below $473 \mathrm{~K}$. The present work again used tritium tracer techniques to study hydrogen diffusion and trapping in $\mathrm{F} 82 \mathrm{H}$. Instead of the gaseous charging or electrochemical charging previously employed, a DC glow discharge (DCGD) method was used to load much larger amounts of hydrogen, with accompanying defect formation.

\section{$[\mathrm{LF}]$}

\section{Experimental}

Rectangular rods of F82H $\left(4 \times 10 \times 1 \mathrm{~mm}^{3}\right)$ supplied by JAEA were used, after surfaces were mechanically polished to a mirror finish. Hydrogen $(\mathrm{H})$ including a tracer amount of tritium $(\mathrm{T})$ with $\mathrm{T} / \mathrm{H}=10^{-6}$ was loaded into one edge surface of the rod by the DC glow discharge (DCGD) method, while the remaining area was covered by a SS316 cathode electrode. The details of the loading were shown elsewhere [3-5]. The DCGD was conducted in a Pyrex glass tube filled with $\mathrm{H}(\mathrm{T})$ gas at $40 \mathrm{~Pa}$, applying a discharge voltage of $350 \mathrm{~V}$ by a pulsed mode with 1 min discharge and 1 min off for $1 \mathrm{~h}$. The integrated $\mathrm{H}(\mathrm{T})$ loading time was $30 \mathrm{~min}$. In order to prevent $\mathrm{H}(\mathrm{T})$ diffusion into the sample during DCGD, the tube was kept at liquid $\mathrm{N}_{2}$ temperature. After the $\mathrm{H}(\mathrm{T})$ loading, all the sample surfaces except for the $\mathrm{H}(\mathrm{T})$ loaded surface were polished to remove $\mathrm{T}$ contamination. This procedure took $15 \mathrm{~min}$ at RT and could allow some of the loaded $\mathrm{H}(\mathrm{T})$ to diffuse in and release out, which we believe to be a negligibly 
small fraction. Subsequently, two experiments were conducted; i.e. measurements of released T from the surface and depth profiling of T, as schematically illustrated in Fig. 1(a) and (b), respectively. The details of the experimental methods were described in [1,3-6]; briefly, in the case of the T release measurement, the rod was immersed in a liquid scintillation counting (LSC) solution kept at 298 or $323 \mathrm{~K}$ and T released from the rod was collected in the LSC solution (see Fig. 1(a)). The integrated amount of T released to the solution in $10 \mathrm{~min}$ was periodically measured, continuing for $10 \mathrm{~h}$, which gave the T release rates $[1,6]$. Then, assuming the $\mathrm{T} / \mathrm{H}$ ratio in the rod was the same as that in the $\mathrm{H}(\mathrm{T})$ gas, i.e. $\mathrm{T} / \mathrm{H}=10^{-6}$, the $\mathrm{T}$ release rates were converted to $\mathrm{H}$ release rates, $J(t)$.

The surface distribution of $\mathrm{T}$ activity ( $\mathrm{T}$ distribution profile) was determined by a tritium imaging plate (TIP) technique at liquid $\mathrm{N}_{2}$ temperature to inhibit the $\mathrm{H}(\mathrm{T})$ migration during the procedure, as shown in Fig. 1(b) [3-5]. These measurements were made on the side surface of the T loaded rod after holding times of $15 \mathrm{~min}, 1 \mathrm{~h}, 3 \mathrm{~h}$ and $10 \mathrm{~h}$ at a constant temperature, either 298 or $323 \mathrm{~K}$. In separate work [5], we found that the $\mathrm{T}$ distribution profile thus obtained corresponds with the depth concentration profile of $\mathrm{T}$ when surface layers of around $0.1 \mathrm{~mm}$ thickness were removed by mechanical polishing. Figure 1(c) is one of the $\mathrm{T}$ distribution profiles obtained from the rod; black to white gradation from left to right indicates the $\mathrm{T}$ penetration from the loaded surface into the bulk. A concentration profile of $\mathrm{H}, c(x, t)$, averaged to the rod width (y-axis) direction can be obtained by,

$$
c(x, t) \propto \int_{0}^{y_{0}} I_{T}(x, t) d y / y_{0}
$$

where $I_{T}(x, t)$ is the distribution of the T activity observed on the surface (Photo-Luminescence Intensity per unit area, PSL $\mathrm{mm}^{-2}$ ) and $y_{0}$ is the width of the rod.

\section{$[\mathrm{LF}]$}

\section{Results}

Figure 2 (a) shows sequential changes of $\mathrm{H}$ depth concentration profiles for the rod with the holding time of $15 \mathrm{~min}, 1 \mathrm{~h}, 3 \mathrm{~h}$ and $10 \mathrm{~h}$ at $298 \mathrm{~K}$ after $\mathrm{H}(\mathrm{T})$ loading at $200 \mathrm{~K}$. The $\mathrm{H}$ is clearly localized in the near surface region, within $200 \mu \mathrm{m}$, but with some penetrating to greater depths. Therefore the surface localized component $c_{1}(x, t)$ was separated from the remaining deeper distribution, $c_{2}(x, t)$, as indicated in the figure,

$$
c(x, t)=c_{1}(x, t)+c_{2}(x, t),
$$


By integrating the profile over all depths, $x_{0}$, the total amount of $\mathrm{H}$ retained in the rod was obtained,

$$
M(t)=\int_{x=0}^{x_{0}} c(x, t) d x
$$

and plotted against the holding time in Fig. 3. In the figure, one can find that $M(t)$ decreased within the first $3 \mathrm{~h}$ and became nearly constant afterwards, which was attributed to the surface localized component (see Fig. 2(a)) and designated as $M_{1}$. Therefore an amount of component 2, $M_{2}$, was determined by,

$$
M_{2}=\int_{t=0}^{\infty} M(t) d t-M_{1}
$$

The ratio of the integrated amounts $M_{1}$ and $M_{2}$ was $2 / 3$ or $40 \% / 60 \%$.

Figure 4 shows changes of the release rates of $\mathrm{H}$ from the rod with time at 298 and $323 \mathrm{~K}$ measured by the LSC technique, referred to as $J(t)$. The solid lines in the figure are numerically calculated release rates, which are discussed later. The integrated released amount, which should be equivalent to $M_{2}$, was determined to be $9.6 \times 10^{14} \mathrm{H}$ atoms at $298 \mathrm{~K}$ and $4.9 \times 10^{14} \mathrm{H}$ atoms at $323 \mathrm{~K}$. Considering the fugacity of $\mathrm{H}$ during DCGD, which is likely a GPa level of $\mathrm{H}$ pressure [7], and assuming the $\mathrm{H}$ solubility in $\mathrm{F} 82 \mathrm{H}$ is similar to that in pure iron $(\mathrm{Fe})$ at $200 \mathrm{~K}$, the Sievert's law gives the $\mathrm{H}$ concentration of around $10^{-5} \mathrm{H} / \mathrm{Fe}$ atom ratio. Assuming the concentration of $\mathrm{H}$ loaded by DCGD is constant with $\mathrm{H} / \mathrm{Fe}$ nearly equals to 1 within $6 \times 10^{5}$ layers $(200 \mu \mathrm{m})$ of $\mathrm{Fe}$, the retained amount of $\mathrm{H}$ in the layers is estimated to be around $10^{15}$ atoms, which is consistent with the observed depth of around $200 \mu \mathrm{m}$ in Fig. 2 (a). When DCGD was stopped, the fugacity dropped immediately to the $\mathrm{H}$ gas pressure of around $40 \mathrm{~Pa}$, and the $\mathrm{H}$ in the surface layers was oversaturated and hence released from the surface and diffused into deeper. Still some $\mathrm{H}$ was retained or trapped in trapping sites in near surface layers, such as surface oxides, grain boundaries, defects and defect clusters formed by the $\mathrm{H}$ loading during DCGD. Actually, about $40 \%$ of the initially retained amount of $\mathrm{H}$ was remained for a long time in near surface regions, as noted above.

In distinction from the surface localized component, we have tried to determine the apparent diffusion coefficients for the component $2, c_{2}(x, t)$, in the depth profiles as seen in Fig. 2 (b) which shows magnified section of the $\mathrm{H}$ depth profiles, 20 times those given in Fig. 2(a). In the figure, one can clearly see that the $\mathrm{H}$ concentration extends deeper as the holding time increases from $15 \mathrm{~min}$ to $3 \mathrm{~h}$, while that in the deeper region is almost disappeared when the rod was held for $10 \mathrm{~h}$ after the loading due to $\mathrm{H}$ release 
from the rod.

The depth profiles after 1,3 and $10 \mathrm{~h}$ were numerically fitted to a simple solution of the one dimensional Fick's second equation to give the $\mathrm{H}$ concentration profiles shown in Fig. 2 (c). Since we could not get surface boundary condition for $c_{2}(0, t)$ at $\mathrm{t}=0$, because the observed depth profile $c(x, t)$ included the surface localized component, we assumed normal diffusional release of $\mathrm{H}$, i.e. $c_{2}(0, t)=0(\mathrm{t}>$ $0)$ and $c_{2}(\infty, t)=0$. Therefore both the apparent diffusion coefficient and the initial surface concentration $c_{2}(0,0)=c_{0}$ were determined as fitting parameters. The best fit gave the apparent $\mathrm{H}$ diffusion coefficient, $D=5 \pm 2 \times 10^{-12} \mathrm{~m}^{2} \mathrm{~s}^{-1}$ at $298 \mathrm{~K}$ as labeled in Fig. 2 (c). There is a large uncertainty, due to the simultaneous determination of the apparent diffusion coefficient and the initial surface concentration.

From the $\mathrm{H}$ release rate, apparent diffusion coefficients were also determined by fitting the solution of Fick's equation under the same initial and boundary conditions used above and the best fit results are given in Fig. 4. The apparent $\mathrm{H}$ diffusion coefficients thus obtained were about one order of magnitude smaller than those determined by the $\mathrm{H}$ depth profile, but are consistent with our previous results [1] which were determined by the $\mathrm{H}$ release rate.

\section{Discussion}

In Fig. 5, the apparent $\mathrm{H}$ diffusion coefficients obtained in this work are compared with literature data $[1-2,8-9]$. The present values determined from the depth profiling are in agreement with the lower temperature extrapolation of Schliefer's data, as indicated by a solid line in the figure giving the temperature dependence of the diffusion coefficients as $D=7.7 \times 10^{-6} \exp \left(-34.3\left[\mathrm{~kJ} \mathrm{~mol}^{-1}\right] / \mathrm{RT}\right)$, but they are much lower than extrapolation of Serra's [2] and Kulsartov's [9] data evaluated above $573 \mathrm{~K}$ with activation energies of $14.0 \mathrm{~kJ} \mathrm{~mol}^{-1}$ and $8.0 \mathrm{~kJ} \mathrm{~mol}^{-1}$ shown as dotted and dashed lines, respectively. However, the Serra's experimental data, which is bending to lower values below $473 \mathrm{~K}$ when extrapolated to RT (chained line), coincides with the present data determined from the $\mathrm{H}$ release rate. It is well known that diffusion data in bcc Fe are strongly influenced by trapping and/or surface oxidation, resulting in large deviations to lower values [10]. In particular, diffusion coefficients determined by thermal release and/or permeation methods are easily influenced by trapping. Actually those determined here from the $\mathrm{H}$ release rates should be dominated by the slow release of the surface localized component. In this respect, the diffusion coefficients determined from the depth profiling is a more direct measurement of the bulk $\mathrm{H}$ 
diffusion, and the activation energy of $34.3 \mathrm{~kJ} \mathrm{~mol}^{-1}$ obtained here is the most plausible value for the bulk $\mathrm{H}$ diffusion in F82H near RT. Still, it seems very high compared to $14.0 \mathrm{~kJ} \mathrm{~mol}^{-1}$ [2] and $8.0 \mathrm{~kJ} \mathrm{~mol}^{-1}$ [9], indicating the influence of the surface localized $\mathrm{H}$.

At present, the cause of surface localization of $\mathrm{H}$ is not clear, but it likely correlates with a surface oxide with large $\mathrm{H}$ trapping energy. In this respect, $\mathrm{Cr}$, one of the alloy components, is well known to be oxidized even in a hydrogen gas atmosphere by any impurity moisture [10]. Although DCGD could introduce lattice defects in the surface layers, water vapor included in the hydrogen gas could easily react with the defects to enhance oxygen uptake. The influence of surface oxygen or surface oxides on $\mathrm{H}$ or $\mathrm{T}$ uptake is under examination.

\section{$[\mathrm{LF}]$}

\section{Conclusions}

In order to clarify hydrogen behavior in $\mathrm{F} 82 \mathrm{H}$, we have applied tritium tracer techniques. Hydrogen, including a trace amount of T, was loaded on the edge of a F82H rod by DCGD at $200 \mathrm{~K}$. After the loading, the rod was held at 298 or $323 \mathrm{~K}$ for long times to allow $\mathrm{H}$ diffuse in and release from the rod. During the sample holding, $\mathrm{H}$ depth profiles and $\mathrm{H}$ release rates were determined by the TIP technique and by the LSC technique, respectively.

The $\mathrm{H}$ depth profiles were clearly separated into two components; one that had diffused deeply into the bulk and the other highly localized in near surface regions. Correspondingly, $60 \%$ of the initially retained amount was released within first $3 \mathrm{~h}$ as the diffused component and $40 \%$ remained for a long time as a surface localized component. Apparent $\mathrm{H}$ diffusion coefficients determined from the depth profiles in the deeper region are near the extrapolated value of the literature data determined at higher temperatures. The surface localized component was released very slowly to give smaller apparent diffusion coefficients than those determined from the diffused component. The apparent $\mathrm{H}$ diffusion coefficients determined by the depth profiling are more reliable than those determined by the release or permeation, because the influence of the surface localized $\mathrm{H}$ is mostly excluded. The surface localization of $\mathrm{H}$ is very likely caused by trapping at surface oxides, most probably $\mathrm{Cr}$ oxide, and by defects produced by DCGD.

\section{Acknowledgement}


This work was supported by Grant-in-Aid for Scientific Research, Ministry of Education, Culture, Sports of Japanese Government, Priority area 467, “Tritium for Fusion”, No. 20049006, 2009. [Insert Page break] 


\section{References}

[1] T. Otsuka and T. Tanabe, Fusion Sci. Technol. 54 (2008) 541-544.

[2] E. Serra, G. Benamati and O. V. Ogorodnikova, J. Nucl. Mater. 255 (1998) 105-115.

[3] K. Hashizume, J. Masuda, T. Otsuka, et al., J. Nucl. Mater. 367-370 (2007) 876-881.

[4] J. Masuda, K. Hashizume, T. Otsuka, et al., J. Nucl. Mater. 363-365 (2007) 1256-1260.

[5] T. Otsuka, T. Hoshihira and T. Tanabe, Phys. Scri. T 138 (2009) 014052.

[6] T. Otsuka, S. Sasabe and T. Tanabe, J. Nucl. Mater. 386-388 (2009) 884-887.

[7] K. Kamada and A. Sagara, Scr. Met. 22 (1988) 445-450.

[8] F. Schliefer, C. Liu and P. Jung, J. Nucl. Mater. 283-287 (2000) 540-544.

[9] T. V. Kulsartov, K. Hayashi, M. Nakamichi, et al., Fusion Engineering \& Design 81 (2006) 701-705.

[10] T. Tanabe, Y. Yamanishi and S. Imoto, J. Jpn. Inst. Metals 25 (1984) 1-10. 
Figure captions

Fig. 1 Schematics of (a) T release experiment by the LSC technique, (b) T depth profiling experiment by the TIP technique, and (c) T distribution profile at $3 \mathrm{~h}(298 \mathrm{~K})$ after the loading; black to white gradation from left to right in (c) indicates $\mathrm{T}$ penetration from the loaded surface to the deeper into the bulk.

Fig. 2 (a) $\mathrm{H}$ concentration profiles $c(x, t)$ determined by the TIP technique at $15 \mathrm{~min}, 1 \mathrm{~h}, 3 \mathrm{~h}$ and $10 \mathrm{~h}$ held at RT after the $\mathrm{H}(\mathrm{T})$ loading at liquid $\mathrm{N}_{2}$ temperature and (b) their profiles magnified 20 times, and (c) calculated concentration profiles at respective times, assuming $\mathrm{H}$ was initially distributed within $200 \mu \mathrm{m}$ in depth (t=0) with constant concentration and freely diffused into the depth and/or released from the surface.

Fig. 3 Sequential changes of remaining $\mathrm{H}$ in the $\operatorname{rod}, M(t)$, determined by the integration of the depth profiles. Around $60 \%$ of the initially retained $\mathrm{H}$ was released within a few hours and afterwards the release amount remained almost constant.

Fig. 4 Release rates of $\mathrm{H}$ from the rod measured by the LSC technique, $J(t)$, at 298 and $323 \mathrm{~K}$.

Fig. 5 Comparison of hydrogen diffusion coefficients in F82H determined from the depth profiles and the release rates together with literature data [1-2, 8-9]. 
(a)

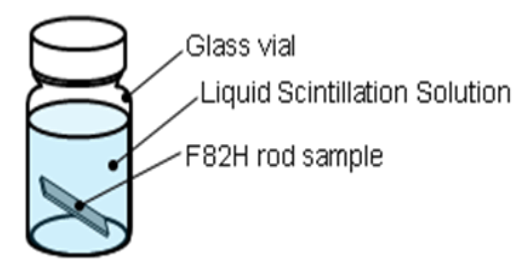

(b)

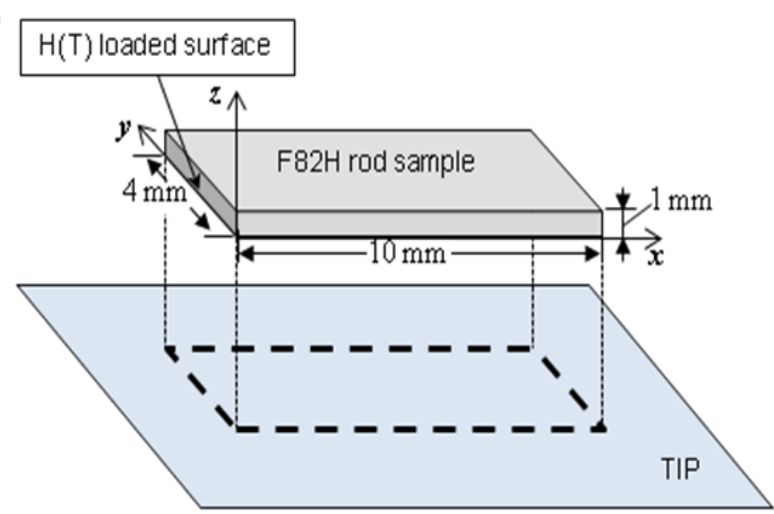

(c)

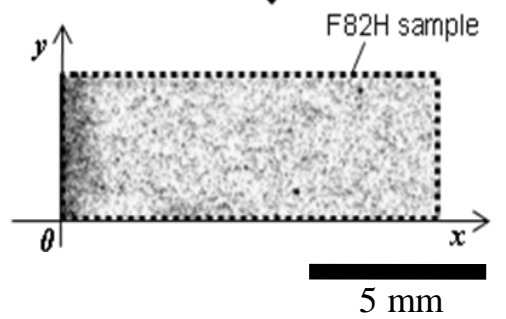

Fig. 1

T. Otsuka, one column 


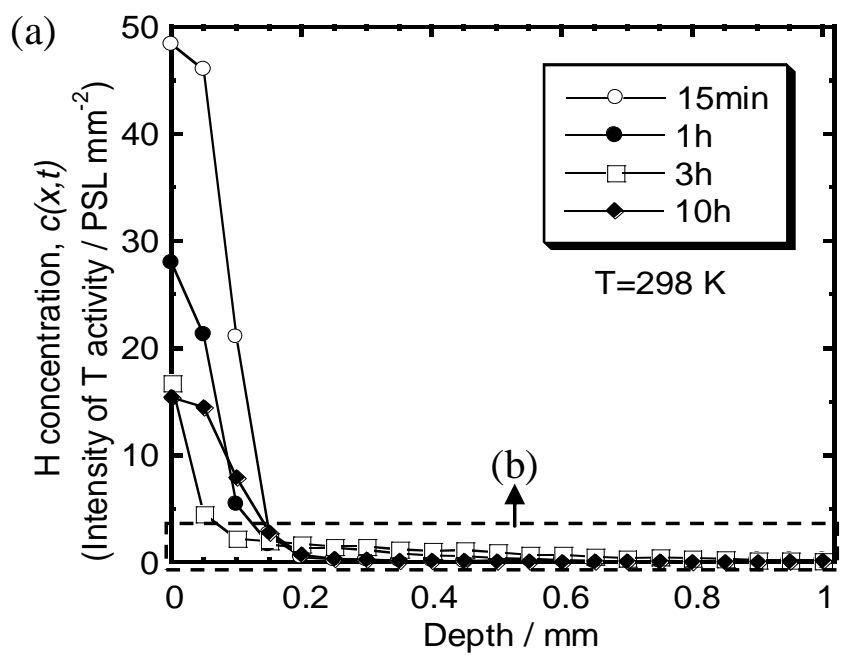

(b)

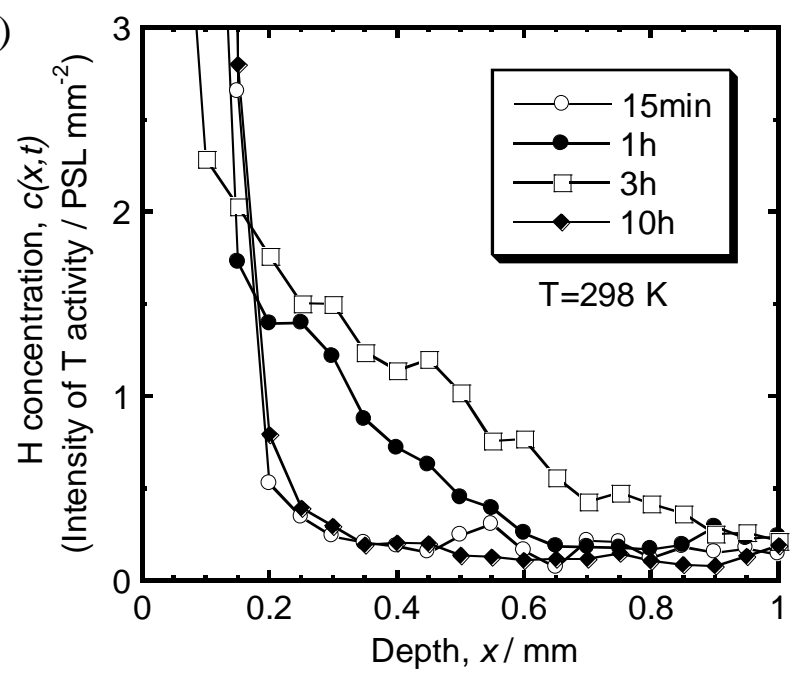

(c)

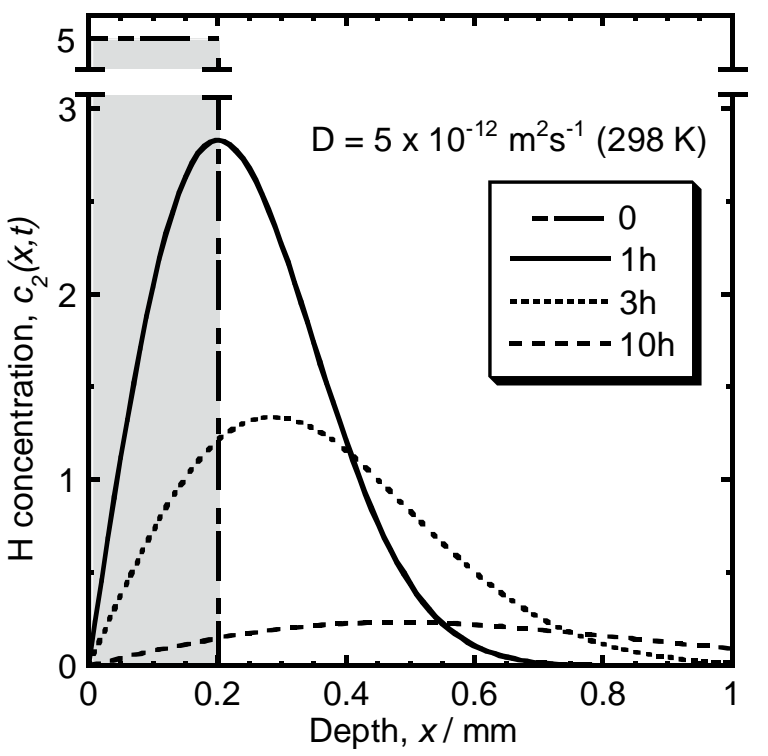

Fig. 2

T. Otsuka, one column 


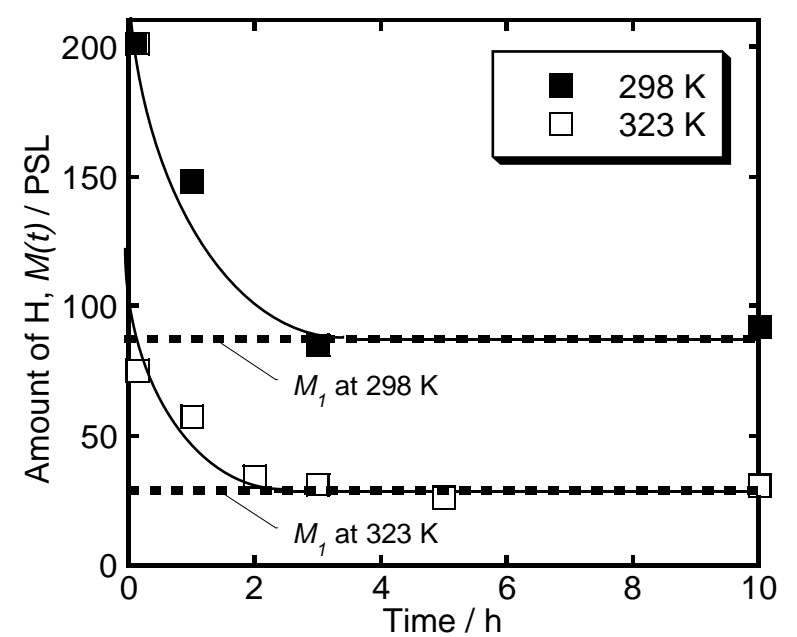

Fig. 3

T. Otsuka, one column 


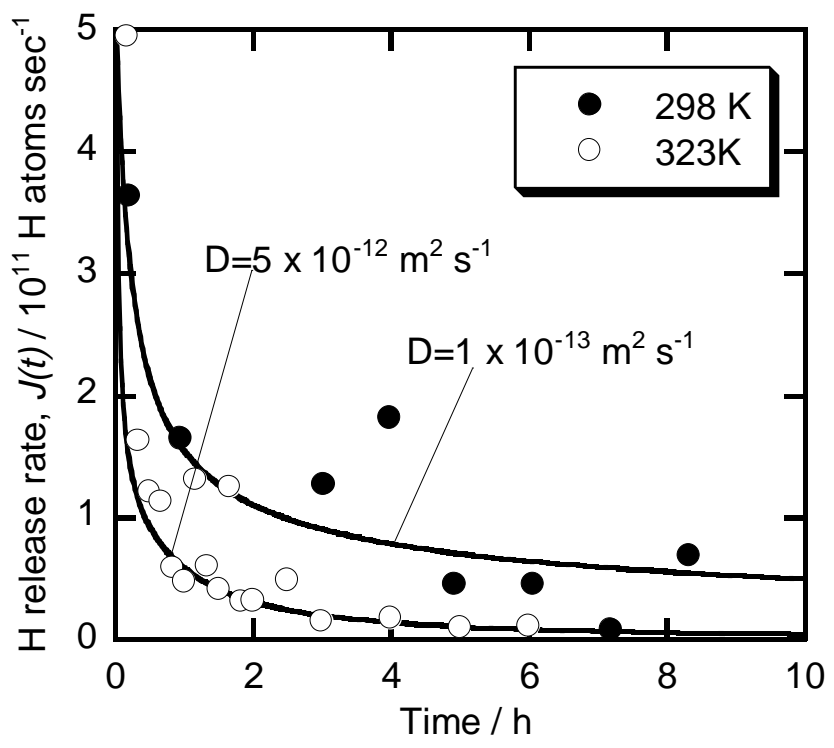

Fig. 4

T. Otsuka, one column 


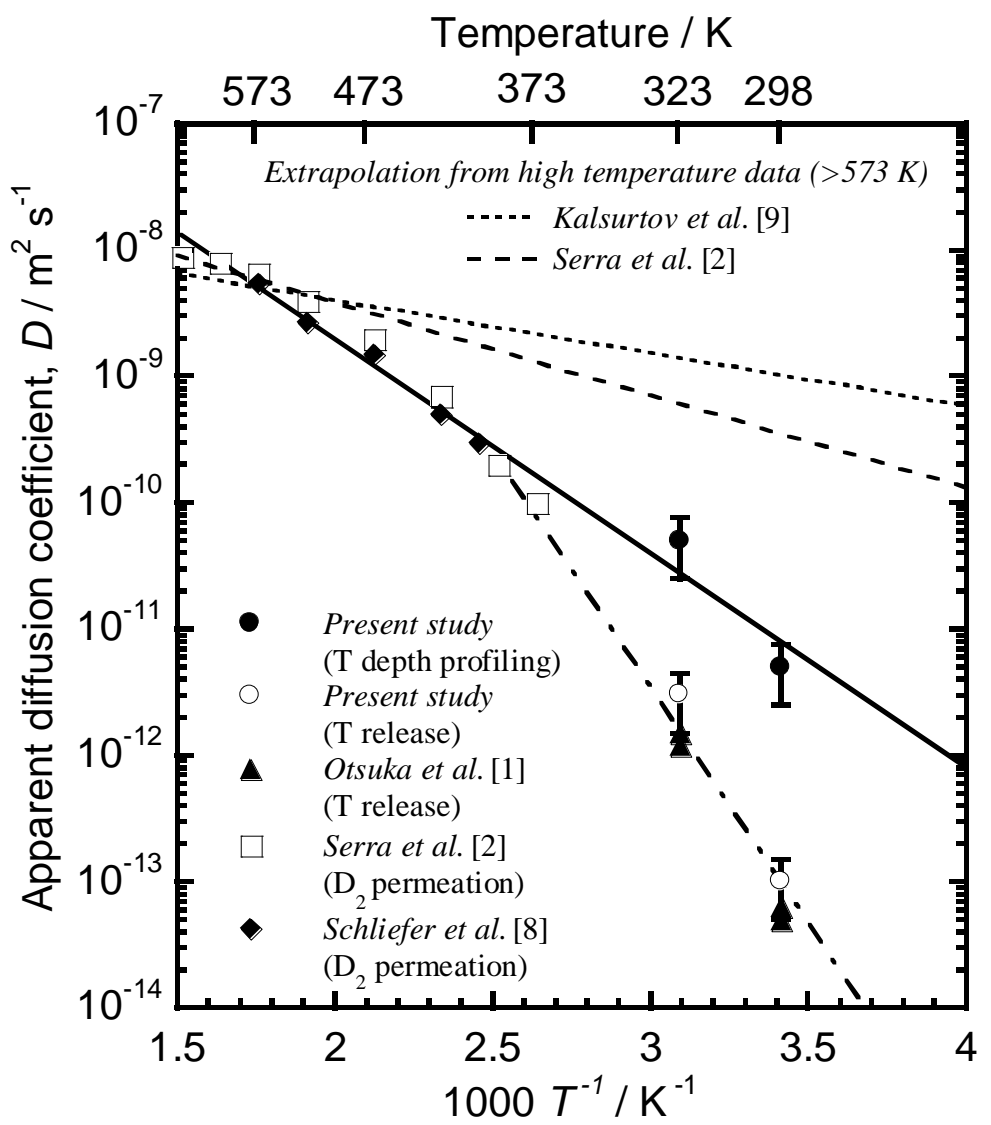

Fig. 5

T. Otsuka, one column 